\title{
Reliability of Oxygen Tension Measurements on Arterialized Capillary Blood in the Newborn
}

\author{
K. R. MOUNTAIN and D. G. CAMPBELL \\ From the Department of Obstetrics and Gynaecology, Melbourne University; \\ and the Pathology Department, The Royal Women's Hospital, Melbourne, Victoria, Australia
}

\begin{abstract}
Mountain, K. R., and Campbell, D. G. (1970). Archives of Disease in Childhood, 45, 134. Reliability of oxygen tension measurements on arterialized capillary blood in the newborn. Samples of blood were obtained from newborn infants simultaneously from an umbilical artery catheter, an 'arterialized' heel, an unprepared heel, and from an 'arterialized' thumb. The correlation between the arterial oxygen tension with that of capillary blood, whether arterialized or not, was poor. Thus it was concluded that arterial blood is the only satisfactory sample for the measurement of oxygen tension in the newborn.
\end{abstract}

A high concentration of oxygen in the incubator is now firmly re-established as a valuable part of the treatment of respiratory distress syndrome of the newborn (RDS), the danger of retrolental fibroplasia being minimal as long as the arterial oxygen tension is kept below approximately 160 $\mathrm{mm}$. $\mathrm{Hg}$. Low oxygen tensions are also to be avoided in babies with RDS to prevent reflex pulmonary vasoconstriction (Chu et al., 1965). To keep the arterial oxygen tension within the fairly narrow range of $70-160 \mathrm{~mm} . \mathrm{Hg}$ in infants with RDS, frequent analysis of arterial blood is necessary.

A catheter inserted into the aorta via an umbilical artery has proved a valuable method of obtaining arterial samples frequently and painlessly. This blood is post-ductal, but Roberton et al. (1968) suggest that if aortic blood oxygen tensions are kept below $100 \mathrm{~mm}$. Hg toxic retinal damage is unlikely, even in the presence of a large right-toleft shunt.

Umbilical artery catheterization is not always successful and arterial blood sampling from other sites such as the temporal artery, (Thomsen, 1964) and the radial artery (Bucci et al., 1966) is associated with an even higher failure rate. Sampling from the thumb and finger has been used (E. Burnard, 1969, personal communication) but this requires incision with a scalpel blade to sever a digital artery. Therefore, inevitably, some babies with RDS receive high concentrations of oxygen without

Received 14 July 1969. measurement of oxygen tension in arterial blo samples. From 1965 to 1967 'arterialized' capillawy blood was used in this hospital for the measurement of oxygen tension in patients where $\vec{\Omega} \overrightarrow{\mathrm{ro}}$ arterial catheter was inserted. However, a case permanent retrolental fibroplasia, occurring baby in whom frequently measured 'arterializea' capillary oxygen tensions were never above 1 (1) $\mathrm{mm}$. $\mathrm{Hg}$, led to an investigation into the validify of this method. A satisfactory correlation between capillary and arterial oxygen values has been show

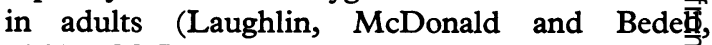
1964; McIntyre, Norman, and Smith 1968, but no information was available until recent (Koch and Wendel, 1967) with respect to the newborn infant.

This paper describes the correlation between capillary and arterial oxygen tensions in a group of newborn infants.

\section{Materials and Methods}

Initially 47 babies were studied. The only criter for inclusion in the study were that an umbilical arteris catheter be in situ, and that the baby be not so ill that simultaneous multiple punctures of both heels woulg jeopardize his chances of recovery. The majorify of babies were ill; 24 had respiratory illnesses, and 23 had apparently normal cardio-pulmonary systems be had a variety of neonatal conditions as set out in Table $\Psi_{\text {. }}$ The weights, gestation periods, and ages of the babies are set out in Tables II, III, and IV.

Blood was collected from 3 different sites simultan $\frac{\Gamma}{6}$ ously by 3 individuals independently, arterial blood from an umbilical artery catheter, capillary blood from 
TABLE I

Neonatal Conditions of Babies Studied

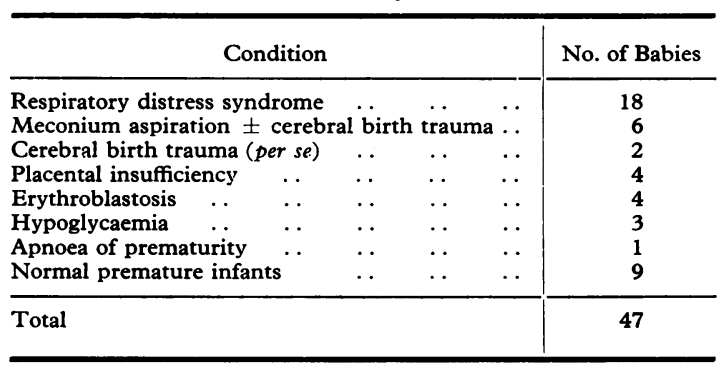

an 'arterialized' heel, and capillary blood from an unprepared heel. In 14 babies blood was also collected from the pulp of an 'arterialized' thumb. All collections were begun at precisely the same time, being initiated by an independent observer who also timed the whole procedure.

The 'arterialized' heel was prepared by wrapping the foot and lower leg in a heated cloth for 10 minutes before the collections began. The cloth was heated by immersing it in hot water and replacing it every 2 minutes. The other heel was unprepared. 6 heparinized capillary tubes were collected successively from each heel, after the method of Siggaard Andersen et al. (1960), each tube being timed in seconds to give some objective idea of the degree of difficulty of collection.

Before the collection of the arterial sample the $10 \%$ solution of dextrose in the catheter was withdrawn until pure blood was obtained. Then a fresh $2 \mathrm{ml}$. plastic disposable syringe, with the dead-space filled with heparin solution and containing a metal washer for stirring purposes, was transferred to the end of the umbilical artery catheter and the sample of arterial blood withdrawn, care being taken to exclude air bubbles. After $1 \mathrm{ml}$. of arterial blood had been collected a needle was then attached to the syringe, any small air bubbles extruded and the needle stuck into a rubber stopper to seal the sample. In the last 26 patients of the study a sample of umbilical arterial blood was collected both with the collection of the first capillary tube and with the collection of the last, and separately analysed to ascertain the change in the baby's arterial oxygen tension during the collection of the capillary tubes. Sampling sometimes took as long as 11 minutes during which time the infant usually cried. The specimens were transported at room temperature to the laboratory without delay for analysis.

Finally, a separate group of babies was studied in which extreme precautions were taken to eliminate the effect of temperature and delay on the samples. 15 babies were studied in exactly the manner described above except that the samples were transferred immediately on collection into a plastic box filled with crushed ice and transported to the laboratory for analysis with the minimum of delay. Every effort was made to minimize the time that the samples were in contact with
TABLE II

Birthweights of Babies Studied

\begin{tabular}{c|c}
\hline Weight (g.) & No. of Babies \\
\hline$<1500$ & 14 \\
$1500-2500$ & 15 \\
$>2500$ & 18 \\
\hline Total & 47
\end{tabular}

TABLE III

Gestation Periods of Babies Studied

\begin{tabular}{c|c}
\hline Gestation Period (wk.) & No. of Babies \\
\hline$<32$ & 12 \\
$32-36$ & 16 \\
$>36$ & 19 \\
\hline Total & 47
\end{tabular}

TABLE IV

Ages of Babies Studied

\begin{tabular}{c|c}
\hline Age (hr.) & No. of Babies \\
\hline$<24$ & 17 \\
$24-48$ & 17 \\
13 \\
\hline Total & 47
\end{tabular}

room temperature by having separate people sealing and stirring each tube as soon as it was collected and then transferring it immediately to the ice-cold environment of the plastic box. These last 15 babies were all normal babies at term within 3 to 9 hours of delivery who had an umbilical artery catheter inserted for the 5 to 10 minutes it took to collect the capillary samples and then immediately withdrawn. Permission for this procedure was always obtained from the mother after the reason for the study and the risks had been explained.*

*Following an inquiry by the Editors on the ethical aspects of their investigations, the authors write: 'It was decided that, as the 'message' was so important, it was justified to pass a catheter on healthy babies purely for the purpose of the study as long as: (1) the permission of the parents was obtained; (2) the procedure was done under strict aseptic conditions: (3) the catheter was in place only for the length of time necessary to collect capillary samples, and then immediately withdrawn in a slow stepwise fashion, allowing the vessel to clot proximal to the catheter; (4) that haemostasis be secured by means of a purse-string suture inserted before the insertion of the catheter, and tightened on its withdrawal; (5) that the end of the catheter be sent for culture after its withdrawal in case of subsequent infection; (6) that the baby be observed carefully half-hourly for 12 hours after the procedure; (7) if the catheter had not readily entered the artery, the attempt would have been promptly abandoned.

All of these conditions were met with in all 15 babies and none suffered any harm as a result of the procedure. After all, the main risks of umbilical artery catheterization are a direct result of the catheter being left in situ for many hours. The mother of each baby was interviewed beforehand and her permission obtained. The situation was carefully explained, it being made clear that the test would be of no direct benefit to her baby but may be of much benefit to other babies in the future.' 
The ambient oxygen concentration was measured at the beginning and the end of each procedure.

Technical methods. All measurements were made at $38{ }^{\circ} \mathrm{C}$. Samples were analysed as soon as possible after receipt in the laboratory and were stored at $4{ }^{\circ} \mathrm{C}$. while awaiting analysis. Measurements were made with a Clark type of polarographic electrode (Radiometer Type E 5046) that was standardized at an oxygen tension of $0 \mathrm{~mm}$. $\mathrm{Hg}$ by means of dithionite in borate solution and at about $150 \mathrm{~mm}$. $\mathrm{Hg}$ with water from the circulation tank of a Micro Astrup instrument. If it was possible to obtain more than one reading on a patient's sample, the average result was taken. These samples were analysed by the staff as part of the routine work of the Biochemistry Department.

The oxygen concentration in the Isolette was measured by means of a 'Mira' oxygen analyser.

\section{Results}

It was found that there was very poor correlation between aortic oxygen tension and 'arterialized' capillary oxygen tension. The correlation coefficient was $+0 \cdot 50, t=3 \cdot 74$ and $p<0.001$. Fig. 1 shows the results graphically. Most of the points

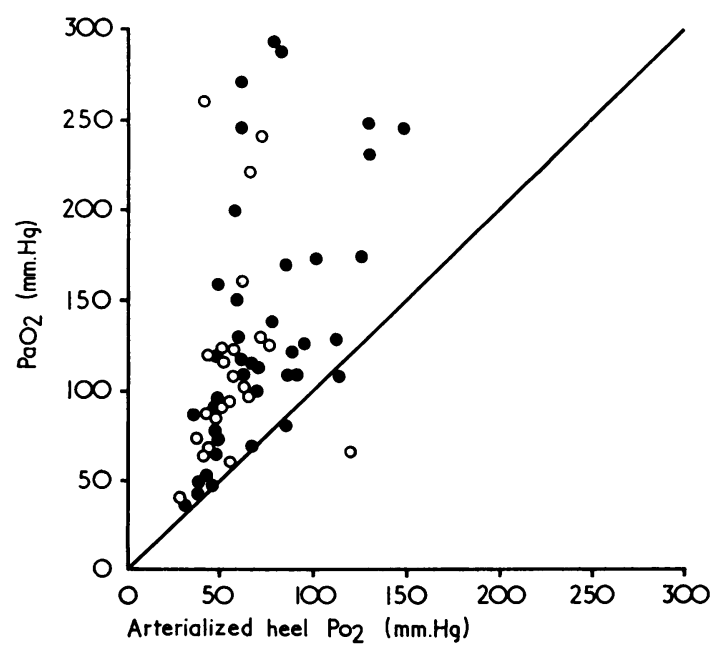

Fig. 1.-Comparison of oxygen tensions in umbilical artery blood and in capillary blood from an 'arterialized' heel. The open circles represent babies with RDS.

lie above the $45^{\circ}$ line showing that capillary oxygen tension was almost always lower than the aortic oxygen tension. The majority of differences were clinically significant and were more pronounced at higher arterial oxygen tensions. No 'arterialized' capillary oxygen tension occurred in the range considered dangerous to the neonatal retina yêt many of the arterial values were well into this rang:

The regression equation for the arterial oxygen tension from the arterialized capillary value was,: aortic oxygen tension $=(1.0 \times$ 'arterialized capillary value $+50 \mathrm{~mm}$. $\mathrm{Hg}$ ) with a standaed error (SE) of $50 \mathrm{~mm}$. $\mathrm{Hg}$. The results from the unprepared heel were worse: $r=+0 \cdot 25, t=1 \cdot 9$, and $0 \cdot 10>p>0 \cdot 05$. The SE of the arterial oxygen tension calculated from the unprepared capillafy value was $72 \mathrm{~mm}$. $\mathrm{Hg}$. In the remainder of the results only 'arterialized' capillary values will be considered.

The length of time of collection of each capillauy tube bore no relation to the accuracy of the resulss. A tube that was collected in 10 seconds could git just as inaccurate results as a tube that took 19 seconds to collect.

The arterial oxygen tension frequently fed during the time taken to obtain 6 capillary tubes. In half of the patients this fall was $15 \%$ or more of the original value.

The percentage of oxygen within the Isoletwe fell by more than $5 \%$ while the portholes were open for the collection of samples in 21 of the experiments.

In two-thirds of all those studied, the oxygen sion obtained from the sixth capillary tube 4 w\$ higher than that of the first in spite of the frequent fall in the arterial oxygen concentration. Howeve the mean rise from the first to the sixth tube wo only $2 \mathrm{~mm}$. $\mathrm{Hg}$, and the calculated arterial valgie based on the sixth capillary tube would still unreliable (SE of $57 \mathrm{~mm}$. $\mathrm{Hg}$ ).

Fig. 2 shows that in a limited number of casess capillary blood from an 'arterialized' thumb was not more accurate.

The open circles in Fig. 1 represent the babies with RDS. These lie more to the left of the gragh than the main group, indicating that the error wes more pronounced in babies with respirato distress. The mean arterio-capillary differenge for infants with RDS was $66 \mathrm{~mm}$. $\mathrm{Hg}$, while that jf the group with normal lungs was $36 \mathrm{~mm}$. Ig (Table V). This difference between the two meang is significant $(0.05>\mathrm{p}>0.01)$.

Table $\mathrm{V}$ also shows the mean arterio-capilla differences for varying ages and gestation periods. Neither age nor gestation period had a significaligt effect upon the mean arterio-capillary oxygef difference ( $p>0 \cdot 10$ in all cases).

The results from the group in which spechal care was taken to eliminate most of the error dy to continued red cell metabolism were not betfer than those from the original 47 cases. Though 
the correlation coefficient was $+0 \cdot 80, t=4.52$, and $\mathrm{p}<0.001$, the SE of the calculated arterial value was still high, $62 \mathrm{~mm}$. $\mathrm{Hg}$. capillary samples are not satisfactory for the estimation of arterial oxygen tension. Though a regression formula can be calculated, the SE of the arterial oxygen tension estimated from the capillary value is so large $(50 \mathrm{~mm} . \mathrm{Hg})$ as to make the value clinically useless. The result may indicate the lowest value of oxygen tension possible in the artery but uncertainty as to the upper limit is much too great.

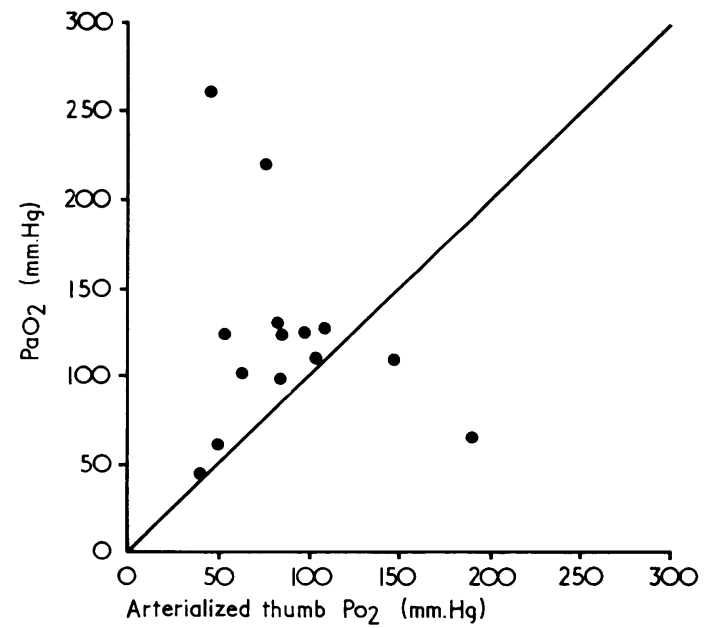

Fig. 2.-Comparison of oxygen tensions in umbilical artery blood and in capillary blood from an 'arterialized' thumb.

The cause of the difference between arterial and capillary samples is unknown. Capillary sampling is subject to more variation than sampling from an arterial catheter, while local temperature, tissue perfusion, and tissue metabolism may all affect

\section{Discussion}

The results described in this paper show that within the first few days after birth 'arterialized'

the value. The sluggish peripheral circulation in the neonate seems the most likely explanation, but in this study we were not able to correct the difference by conscientious warming of the tissue from which capillary samples were to be taken. The time taken to obtain a sample can be quite variable, anything from 5 to $120 \mathrm{sec}$. in this study, during which time the arterial oxygen tension may change due to the baby crying, to a fall in the oxygen concentration within the Isolette, or to changes in local perfusion. When the oxygen concentration within the Isolette is high the blood may actually take up oxygen while exposed on the skin during sampling (Mountain and Campbell, 1969, unpublished observations). This could be the explanation for the few occasions when the capillary sample has a higher value than the arterial sample. The fact that the second and later capillary samples tended to give a higher oxygen result could indicate improved capillary blood flow but the difference between the sixth sample and the arterial value was still too great to allow useful prediction of the arterial value to be made.

A diminution in the blood flow to the limbs of babies with RDS has been shown by plethysmographic studies (Kidd et al., 1966), so it was not surprising to find that the difference was greater in babies with RDS, the very patients in whom accurate results are needed.

It was not possible to show that there was any difference in results when samples were immediately placed on ice as they were collected from the baby, as compared with those that were cooled only after receipt in the laboratory. In separate tests on blood stored for an hour at room temperature there was no difference in the rate of fall of oxygen tension between samples stored in glass capillary tubes or the $2 \mathrm{ml}$. plastic syringes used in this work (Mountain and Campbell, 1969 unpublished observations).

In the practical management of the infant requiring measurement of arterial blood oxygen tensions, knowing the cause of the difference between arterial

TABLE V

Mean Arterio-capillary Oxygen Tension Difference According to Period of Gestation, Age, and Presence of $R D S$

\begin{tabular}{|c|c|c|c|c|c|c|c|c|}
\hline & \multicolumn{3}{|c|}{ Gestation Period (wk) } & \multicolumn{3}{|c|}{ Age (hr.) } & \multicolumn{2}{|c|}{ RDS } \\
\hline & $<32$ & $32-36$ & $>36$ & $<24$ & $24-48$ & $>48$ & Absent & Present \\
\hline $\begin{array}{l}\text { No. of babies } \\
\text { Mean (mm. Hg) } \\
\text { S.E. }\end{array}$ & $\begin{array}{l}13 \\
35 \\
13\end{array}$ & $\begin{array}{l}15 \\
63 \\
15\end{array}$ & $\begin{array}{r}19 \\
47 \\
8\end{array}$ & $\begin{array}{l}17 \\
61 \\
14\end{array}$ & $\begin{array}{l}17 \\
45 \\
10\end{array}$ & $\begin{array}{l}13 \\
42 \\
13\end{array}$ & $\begin{array}{r}24 \\
36 \\
7\end{array}$ & $\begin{array}{l}23 \\
66 \\
12\end{array}$ \\
\hline
\end{tabular}


and capillary values is only useful if it can be recognized and corrected. No correctable factor has been found during this study, and it must be concluded that capillary blood oxygen tensions do not have a place in the management of oxygen therapy in the newborn.

We wish to thank Sisters P. S. Taylor, M. W. Kirk, and M. H. Johnstone of the Royal Women's Hospital, for their patience and assistance with the collection of the numerous capillary samples, the technical staff in the Biochemistry Department for the analysis of the samples, and Dr. W. H. Kitchen for much helpful advice and criticism. We are grateful to the Honorary Paediatricians for access to their patients.

\section{REFERENCES}

Bucci, G., Scalamandrè, A., Savignoni, P. G., Orzalesi, M., and Mendicini, M. (1966). Crib-side sampling of blood from the radial artery. Pediatrics, 37, 497.

Chu, J., Clements, J. A., Cotton, E., Klaus, M. H., Sweet, A. Y., Thomas, M. A., and Tooley, W. H. (1965). The pulmonary hypoperfusion syndrome. Preliminary report. ibid., 35, 733.
Kidd, L., Levison, H., Gemmel, P., Aharon, A., and Swyer, P. R (1966). Limb flow in the normal and sick newborn. America Fournal of Diseases of Children, 112, 462.

Koch, G., and Wendel, H. (1967). Comparison of pH, carbon dioxide tension, standard bicarbonate and oxygen tension capillary blood and in arterial blood during the neonatal perio $f$ Acta Paediatrica Scandinavica, 56, 10.

Laughlin, D. E., McDonald, J. S., and Bedell, G. N. (1964). microtechnique for measurement of $\mathrm{PO}_{2}$ in 'arterialized' earlo blood. Fournal of Laboratory and Clinical Medicine, 64, 330.

McIntyre, J. E., Norman, J. N., and Smith, G. (1968). Use capillary blood in measurement of arterial $\mathrm{Po}_{2}$. British Medical

Fournal, 3, 640.
Roberton, N. C. R., Gupta, J. M., Dahlenburg, G. W., and Tizarep, J. P. M. (1968). Oxygen therapy in the newborn. Lancet $1,1323$.

Siggaard Andersen, O., Engel, K., Jørgensen, K., and Astrup, $\underline{\mathbf{P}_{\text {t }}}$ (1960). A micro method for determination of $\mathrm{pH}$, carbø0 dioxide tension, base excess and standard bicarbonate fR capillary blood. Scandinavian fournal of Clinical and Laboratopi Investigation, 12, 172.

Thomsen, A. (1964). Arterial blood sampling in small infanff. Acta Paediatrica, 53, 237.

Correspondence to Dr. K. R. Mountain, Department of Obstetrics and Gynaecology, University of Melbourne Royal Women's Hospital, Melbourne, Australia. 